\title{
ENTREVISTA
}

\section{Entrevista concedida a Tânia Rosa Ferreira Cascaes por Dra. Nádia T. Covolan}

\section{Notas da Entrevistadora}

Credita-se a um periódico eletrônico de uma Universidade, a abordagem de temas relevantes e que sejam pertinentes a uma sociedade em mudanças e cujos formatos neste cenário se fazem necessários.

Chamar atenção para esses temas é o primeiro passo para incentivar o engajamento do acadêmico nas questões que permeiam os espaços na sociedade, pois como cidadão que é, uma vez inserido no mundo do trabalho, passará a engrossar o coro dos formadores de opinião, já com um olhar diferente pelas sensibilizações adquiridas.

A entrevistada da vez é a Professora Nádia T. Covolan, graduada em Enfermagem e Filosofia, Mestre em Tecnologia e Doutora em Ciências Humanas, é docente da UFPR Setor Litoral e uma das fundadoras do REGEDI, a qual os leitores terão a oportunidade de conhecer na entrevista que segue.

Esta é a nossa contribuição enquanto E'ducadores/as!

Prof. a Tânia Rosa F. Cascaes ${ }^{1}$

Entrevista

\begin{abstract}
“A compreensão multidimensional da complexa e dinâmica gama de significados do que vem a ser o masculino e o feminino na sociedade, implica diretamente no cotidiano, impregna os saberes e fazeres, as práticas educacionais e tecnológicas, as representações individuais e sociais, enfim, embasa, é constituinte e instituinte do "mundo da vida", sendo, portanto, a base imprescindível para a educação "libertadora" com vistas à cidadania."
\end{abstract}

\footnotetext{
${ }^{1}$ Socióloga, Mestre em Tecnologia, membro do Centro de Letras do Paraná e da Academia de Letras José de Alencar, Membro do GETEC - UTFPR e Entrevistadora da Revista Divers@ ! E-mail: taniarosa@onda.com.br.
} 
Os autores da reflexão acima, professores da UFPR Litoral, formaram o Grupo Interdisciplinar de Estudos, Ensino, Pesquisa e Extensão em Representações de Gênero e Diversidade - REGEDI, em 2006, considerando a extrema pertinência do uso da categoria Gênero nas análises e discussões, e como substrato imprescindível na construção dos parâmetros educacionais do Setor. Nesse contexto, apresento a seguir a entrevista realizada em 07 de novembro de 2008.

Divers@! Qual o contexto do nascimento de um Grupo de Estudos sobre Relações de Gênero e Diversidade em um Setor recém implantado, como o da UFPR Litoral?

Prof. ${ }^{a}$ Nádia: O nosso grupo de estudos nasceu no primeiro ano de implantação do Setor Litoral. Eu já fazia parte do GETEC (Grupo de Gênero e Tecnologia) da UTFPR desde sua fundação, há dez anos, e quando assumi a atividade docente aqui no litoral, introduzi a categoria gênero na análise dos temas, em alguns módulos organizados para os cursos Técnico em Enfermagem e a Graduação em Serviço Social; isso foi aglutinando colegas com o mesmo interesse, e em formar um grupo de estudos; foi assim que iniciamos reuniões com os professores Daniel e Marcos, as professoras Silvana, Helena, Stephanie, Dione, de diferentes formações, tendo Gênero como uma categoria aglutinadora de variadas dimensões, as étnicas, rurais e urbanas, de saúde, de ambiente, sexuais, enfim, gênero e diversidade!

\section{Divers@! Quais os modelos que inspiraram a criação do REGEDI?}

Prof. ${ }^{a}$ Nádia: Pensamos a principio num grupo de estudos onde algumas professoras e professores se reunissem para estudar autoras e autores, alguns textos selecionados e discutir temas pertinentes a nossas áreas de interesses comuns e particulares, utilizando gênero como categoria de análise, e que mantivesse vinculo estreito com nosso projeto pedagógico institucional; assim, estamos ainda construindo o grupo, ou seja, queremos um grupo que agregue a categoria gênero mas que pense a diversidade humana, na indissociabilidade ensino, pesquisa, extensão; por isso, esse nome tão longo, REGEDI: grupo interdisciplinar de estudos, ensino/pesquisa/extensão sobre representações de gênero e diversidade.

Divers@! Constatando a emergência do assunto no atual momento das relações sociais como um todo, qual a contribuição deste GRUPO?

Prof. ${ }^{a}$ Nádia: Creio que fazemos a diferença. Gênero e uma categoria fundamental para a compreensão da realidade local e global. Nossa sociedade é organizada sobre bases de gênero 


\section{DIVERS@!}

muito forte, bases assimétricas, com valência negativa para o feminino e com propensão a construir masculinidades opressoras e oprimidas. Se quisermos maior equidade de gênero e justiça social, teremos que investir nas abordagens de gênero e saúde, gênero e meio ambiente, gênero e trabalho, gênero na questão urbana e rural, gênero e Academia, gênero e mídia, gênero e educação, gênero e internet, e assim por diante. Essas dimensões, interfaces, se entrecruzam e suas análises podem iluminar os agenciamentos das consciências, masculinas e femininas. Temos uma heterossexualidade formadora e fundadora do social, que facilmente extrapola para a violência de gênero e a homofobia.

\section{Divers@! Não seria mais produtivo enfocar apenas um dos recortes da Diversidade?}

Prof. ${ }^{a}$ Nádia: Seria mais fácil, entretanto a nossa proposta tem sido muito produtiva. Nós somos um Setor cujo projeto pedagógico prima pela interdisciplinaridade, e as professoras e professores que fazem parte do grupo, também tem diferentes formações e interesses. Nós trabalhamos com o olhar de gênero, utilizamos gênero como uma das possíveis categorias de análise de situações e problemas, categoria imprescindível se quisermos pensar a justiça equitativa e o desenvolvimento. É exatamente pela possibilidade de diversificar o olhar que aglutinamos interesses diversos; a categoria tem reunido outras pessoas interessadas nas questões de religiosidade, campo/urbano, saúde, educação, sexualidade, etnia, entre outras que compõem a realidade humana.

\section{Divers@! Este é um grupo fechado de interessados no tema?}

Prof. ${ }^{a}$ Nádia: É um grupo com pessoas que trabalham diretamente com Gênero, e outras que não trabalham diretamente com a categoria, mas que são sensíveis a ela, reconhecem sua importância na abordagem do social, e, portanto, são do grupo, como a professora Luciana que é nossa artista, o professor Diomar, ligado à revista DIVERS@!, por exemplo. Temos os estudantes de monitoria, duas já formadas, mas que nos auxiliam nas atividades, ou seja, temos um vinculo forte de grupo. Nós também solicitamos colegas para nos auxiliar em temas específicos, neste ano 2008, por exemplo, foi inestimável a contribuição da Regina, estudante de Fisioterapia, dos professores Antonio Sandro do Serviço Social e Emerson, nosso matemático! 


\section{Divers@! Quais as contribuições do grupo para a comunidade acadêmica e para o litoral?}

Prof. ${ }^{a}$ Nádia: O REGEDI já tem uma história de atividades impactantes. Responder esta tua pergunta requer falar das atividades do grupo desde o início, das oficinas nos módulos, das pesquisas e dos projetos de extensão. Em 2006, quando chegamos ao Setor Litoral, nas oficinas de "Gênero e Saúde" e "Gênero e Mídia", realizadas nos cursos, a categoria era novidade até para muitos colegas professoras e professores. Ainda em 2006, o GETEC, Grupo de Gênero e Tecnologia da UTFPR de Curitiba, propôs parceria conosco, para participarmos do edital do Brasil Sem Homofobia do MEC. Nós contatamos a Secretaria da Educação de Matinhos, que confirmou a demanda existente nesse tema, nas escolas da cidade. Ganhamos o edital, e realizamos em Matinhos a capacitação "Refletindo Gênero", que durou todo o ano 2007 e alcançou mais de cem profissionais da educação das esferas municipais e também estaduais. Elaboramos cinco cadernos desse trabalho que em breve serão publicados. Realizamos duas exposições artísticas com professoras do grupo, a Stephanie Dan Batista e Luciana Ferreira; realizamos dois eventos de muita importância no Setor, o primeiro, trazendo a professora Claudia Ribeiro e o segundo, Rogério Diniz do MEC. Também introduzimos a reflexão de Gênero e Diversidade no espaço ICH (Interações Culturais e Humanísticas) sensibilizando estudantes de vários cursos para a temática. Neste ano (2008) implementamos o projeto de combate à violência doméstica no litoral, do edital da SETI (Secretaria de Ciência e Tecnologia do Paraná); estamos no momento encerrando esta atividade com nove estagiários e produção expressiva em termos de pesquisa quanti e qualitativa, artigos, eventos, oficinas, iniciação científica, monitorias e estudantes bolsistas, com participação em congressos e outras atividades relacionadas ao ensino, pesquisa e extensão. Tivemos uma grande vitória, já temos o ISSN da revista DIVERS@!, fruto de um trabalho intenso e conjunto, no qual a professora Mariana iniciou a sua organização, e hoje, Silvana, Gabriela Bica e o professor Diomar são os principais responsáveis. Nossas atividades podem ser encontradas nos sites da UFPR Litoral.

\section{Divers@! Quais as dificuldades encontradas pelo grupo nesse percurso?}

Prof. ${ }^{a}$ Nádia: Creio que as mesmas dificuldades que os grupos de estudos sobre gênero encontram na Academia. O desconhecimento da categoria pela maioria das pessoas, ainda, é um grande entrave, gera certo pré-conceito. Pensamos também que talvez as atividades de extensão venham contribuindo para a impressão e confusão de que os estudos de gênero são 


\section{DIVERS@!}

estudos exclusivos sobre a mulher. Nossos cursos têm grande contingente feminino, tanto os diurnos quanto os noturnos, e essas mulheres são como os homens, estudantes, trabalhadores, pais e mães, enfim, atores sociais que constroem nossa história; esta pode ser construída com mais liberdade e equidade. Temos enfocado a característica relacional da categoria gênero, é com esse enfoque que trabalhamos. Gênero é uma categoria de análise histórica e social das relações que se estabelecem entre as masculinidades e feminilidades, e que têm necessariamente interfaces étnicas, geracionais, urbana/campo, de camadas sociais, de orientação sexual, religiosidades, dentre outras que compõem a humanidade.

\section{Divers@! Quais os planos do Grupo para 2009?}

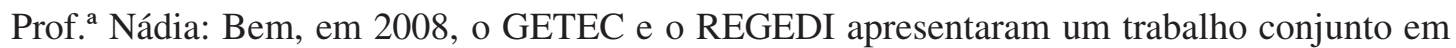
Cuba, e em 2009, apresentaremos outro no Fórum Social Mundial, em Belém do Pará. Isto nos estimula a buscar ampliar as parcerias com outros grupos de gênero nas universidades brasileiras e da América Latina para eventos, estudos, pesquisas, debates e principalmente trocas de experiências. Outra meta de curto prazo é ampliar a participação das e dos estudantes, com as iniciações científicas e prosseguir orientando projetos com essas temáticas.

Divers@!: Bem, eu agradeço essa entrevista e desejo sucesso a todo grupo.

Obrigada a você por participar conosco desta construção.

\section{Entrevistada}

Prof $^{a}$. Dr ${ }^{a}$. Nádia Terezinha Covolan

Doutora Interdisciplinar em Ciências Humanas (UFSC/2005), Mestre em Tecnologia (CEFET-PR/2001), Graduação em Filosofia (UFPR/1989), Graduação em Enfermagem (UFSC?1979). Especialista em Pensamento contemporâneo, Saúde Pública e do Trabalho. Docente da UFPR Setor Litoral, Paraná, atua nas áreas das Ciências Humanas e da Saúde, especialmente com filosofia da técnica e da tecnologia nas dimensões Ética e Bioética. Representa o REGEDI (Grupos de Estudos em Gênero e Diversidade) da UFPR Litoral desde 2006 e participa do GeTec ( Grupo de Estudos de Gênero e Tecnologia) na UTFPR/Curitiba desde 2000.E-mail: nira1@terra.com.br. 